\title{
Exploring Factors Influencing Financial Planning After Retirement: Structural Equation Modeling Approach
}

\author{
Md. Abdul Jalil, Dzuljastri Abdul Razak and S.M. Ferdous Azam \\ Department of Business Administration, \\ Faculty of Economics and Management Sciences, \\ International Islamic University Malaysia, Kuala Lumpur, Malaysia
}

Received 2012-07-14, Revised 2012-10-12; Accepted 2013-04-20

\begin{abstract}
The study explores the critical factors that influence financial planning after retirement among Malaysians, an area which has somewhat been largely overlooked by the extant literature. The study has used a quantitative method to survey a sample of 170 Malaysian citizens, from various places in the Klang Valley area. Exploratory factor analysis, confirmatory factor analysis and structural equation modeling were used to analyze the data. The results suggest that the paths are interrelated to the casual processes significantly. Furthermore, individual's income or monthly salary is found to be the most important factor influencing financial planning, followed by attitude and culture. The results are mainly favourable to academics and practitioners in Malaysia by contributing an understanding into critical factors that influence people to make financial plan before their retirement. The study provides implications of the findings in the concluding section.
\end{abstract}

Keywords: Financial Planning, Income, Culture, Attitude, Individual Perception

\section{INTRODUCTION}

Financial planning fundamentally refers to the estimation of future incomes, expenses, related issues. A financing plan or financial plan all of which usually refer to the means by which cash will be acquired to cover future expenses, such as for instance, through earning, borrowing or using saved cash. From the company perspective, a financial plan can also be an estimation of cash needs and a decision on how to raise cash, such as through borrowing or issuing additional shares in a company. Meanwhile, Hogarth and Hilgert (2002) explained the term retirement as "Employee's termination of service with an employer referred". It does not mean or include a change in the nature of service by an employee of an employer. It is, therefore, when the employee leaves the labor or workforce. "A US government report defined age discrimination as the rejection of an older worker because of the assumptions on the effect of age on the worker's ability to perform, regardless of whether there was any factual basis for the assumptions" (Gregory, 2001). Retirement planning has been a key area of focus for the relatively new profession of financial planners. According to the Certified Financial Planner Board of Standards 1999, 85\% of people engage the services of a financial planner and seek professional assistance because they want help for their retirement plan. While there was once a standard age for retirement in Malaysia and people could count on their company pension plans or retirement funds to get them through their twilight years. However, it is noticed that people often live longer than the availability of their retirement funds. In fact, there is a growing number of retirees that are dedicated to healthy, good, clean and relaxed living. This is something unprecedented throughout history and besides, the retirees are younger Corresponding Author: Md. Abdul Jalil, Department of Business Administration, Faculty of Economics and Management Sciences, International Islamic University Malaysia, 53100 Kuala Lumpur, Malaysia 
in many ways than ever before. This situation creates challenges in most cases.

Although many warning signs have been issued by the prominent Economists about the financial environment nowadays, around 20 million retirees show no interest of saving at all for their old age retirement funds (Richman, 1993). In this contemporary era, people are showing the tendency to get more concerned about their future financial stability as well as retirement issues, wherein organizations and policy makers are also thinking in line with that (Lim, 2003). According to figures provided by the World Health Organization, by the year 2025, older adults in Asia will account for 58\% of the world's population of older people. Additionally, it is expected that Japan and Singapore will be the forerunners in the "global aging" race. In Singapore, the 2000 Census results indicated that $6.1 \%$ of the population were 65 years and older (SNP, 2000). This figure is expected to increase to $25 \%$ by 2030 , in which one in every four citizens will be aged 60 and above (Lim, 2003). Many people are working longer than in the past in order to prolong their investment period. It helps if we set specific goals so that we have a number to work upon. We should discuss our plans and goals with a financial advisor from the very beginning in order to get the most accurate advice that is customized for our individual needs. Investing in the asset or planning for the individual finance is not only to secure the people's economic security during working period but also after their retirement. The gradual increase in the aged population, together with a longer life expectancy, points to the need and importance of a well-planned personal financial planning. However, most individuals seem to have extremely limited knowledge of financial planning. Accordingly, our study aims at examining the factors influencing decision making on financial planning after retirement. The study will also highlight the Malaysian financial planning market after retirement in order to help financial institutions to design financial planning that may favourably suite Malaysians after retirement. Broadly the research aims to study the critical factors that influence financial planning after retirement. The specific objective is to study the attitude of Malaysians on financial planning after retirement.

\subsection{Literature Review}

Lack of literacy and financial sophistication can have important consequences. For instance, Calvert et al. (2005) shows that, households with greater financial sophistication are more likely to participate in risky asset markets and invest more efficiently. Hilgerth et al.
(2003) demonstrate a strong link between the financial knowledge and the financial behavior. One reason people fail to plan for retirement, or do so unsuccessfully, may be most likely due to the fact that they are financially illiterate, in which case, they may fail to appreciate the role of or may have a hard time solving problems with compound interest, inflation and risk. Some studies have investigated specific areas of personal finance, such as the accuracy of knowledge of Social Security benefits (Bernheim, 1987) or the adequacy of households' life insurance coverage (Auerbach and Kotlikoff, 1991). Additionally, Bernheim (1987) has analyzed some surveys on financial planning that were sponsored by financial institutions. The previous research and investigations recommend that, usually people's financial planning process and their thinking are somehow in primary or elementary stage; that means their financial knowledge is normally weak or poor. Besides, those people may be short of problem-solving skills or abilities that is required to make sophisticated decisions on savings. Nevertheless, they may not consider a systematic planning to be worthwhile, especially if insecurity in income, health and other factors make it hard to define optimal savings and consumption plans. Equally, many institutions of higher education are now offering degree and certificate programs for students interested in pursuing careers in this growing field. But to achieve comfortable retirement, one must replace the income stream that comes from formal work. Therefore, it is important to create other sources of income in order to maximize the potential benefits that can be derived at a retirement period.

\subsection{Income/Salary}

Income is a significant issue in a financial planning especially where there is no relationship between the incomes and the savings among low-income families, but it is closely related with the high-income families. Educational level and housing tenure are not as important for low-income families as those of the highincome families. Low- and high-income families' behaviors are similar with regards to the relationship between how important it is to save and the amount saved. Furthermore, low- and high-income households have similar behaviors with respect to the importance of savings and satisfaction level. An examination of selected financial management attitudes and behaviors of 199 young to middle-aged, low-income Black, white and Hispanic persons in Arizona revealed that a large proportion of each racial group did not save $(36,25$ and 
$38 \%$, respectively) (Hurd, 1990). Among those who did save, a large proportion of each group was dissatisfied with the amount of money they saved $(59,61$ and $56 \%$, respectively). Barber and Odean (2001), with a sample of 672 nonmetropolitan households in Kansas, examined the financial management behavior of households with different levels of financial resources and found that households with low incomes were far less likely than middle- and high-income groups to save a specific amount of money on a regular basis.

The gradual increase in the aged population, together with a longer life expectancy, points to the need and importance of a well-planned personal financial planning (Lim, 2003). One thing we should carefully consider when planning for our retirement and setting aside funds for that end is how much money we feel we will need in order to have the quality of life we hope to have upon retirement. The present provision under statutes such as Social Security and Pensions schemes do not guarantee a certain level of comfort at the time of retirement as it may not yield enough income to assure a comfortable standard of living, or security against costs of health care, or even much less a legacy to pass to one's heirs. A pension plan is a deferred compensation program set up by an employer to establish personal retirement funds for the employees. Benefits that employees receive are usually based on years of employment, employee's income, or some combination of both (James et al., 2002). People are investing their own assets and personal income efficiently to ensure that their economic security can be guaranteed, not only during their working life but also after retirement period of need.

\subsection{Culture}

To evaluate the phenomena based on gender differences, the previous surveys and investigation revealed that women are generally less financially knowledgeable than men. With reference to risk and related factors, usually women are less likely to respond correctly to the information as compared to men in terms of financial planning. Yet some findings focused on the generation differences and emphasized on their perception diversification, the demographic differences remain statistically significant. Retirement plans are one of the most important parts of the total employee's benefit and compensation package. Cost, tax treatment, competitive forces and the nature and value of the social retirement benefits all affect strategic and tactical decisions in this area, both for the employers and the employees. Asia, more so than nearly any other region in the world, is undergoing tremendous change due to technical and environmental influences. Family diameter is another element that function as a key factor of financial planning for retirement. Culturally it differs from nation to nation while picturing an ideal family. In Asia, people prefer to have a large number of family members, however, in the west people tend to keep a nuclear family. Therefore, the larger the family size is the more are they concerned on their financial planning rather than nuclear family. Another thing is taking risk. According to Kennickell et al. (1996), there were some inconsistencies between the individuals' descriptions of their willingness to take risk and the apparent riskiness of their investments. For example, the most entrepreneurial member of the group described himself as unwilling to take any financial risks. Nonetheless, the inconsistencies were more of an exception than the rule and those people who are willing to take risks are probably not doing their financial planning after retirement.

\subsection{Attitude}

Financial planning some time depends on the attitude of the individuals. Bernheim $(1995 ; 1998)$ and Hogarth and Hilgert (2002) reported that, most respondents do not understand financial economics concepts, particularly those relating to bonds, stocks, mutual funds and the working of compound interest; they also report that people often fail to understand loans and interest rates. Besides, most people think that they do not think of their savings in terms of specific purposes for which they put money aside ('retirement money', 'vacation money', 'college money'). Rather, they generally think about risks and returns and the time horizon over which they would need. In some cases, people think retirement planning should be set up in the older age. The term "older people" can be defined in a number of different ways. From 'early retirement' in the mid- to late-fifties, to super-centenarians, aged over 110 years, there is a potential age range of more than 60 years for people who are variously described as "older", "retired", "elderly", "senior" or "pensioner" (Peace and Holland, 2001). The term "pensionable age" is frequently used in official documents as a defining category. The minimum permissible age in retirement housing schemes is usually 55; but more than fourfifths of the respondents in this research were seventy years of age or more, which is similar to the research findings of Fleiss (1985); Williams (1990) and Rolfe et al. (1995). There are perhaps three types of mandatory retirement age, namely the contractual retirement age, the pensionable retirement age and the actual or normal retirement age (Sargeant, 2004). Sometimes people tend to have early retirement for their special financial planning. 


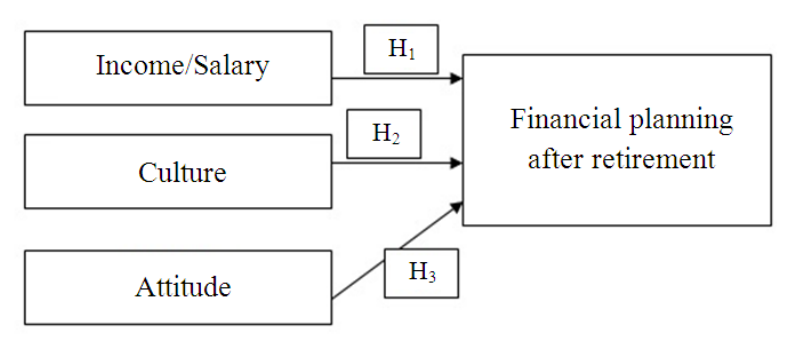

Fig. 1. Factors for financial planning

Early retirement policies are a means of encouraging older workers to exit the workforce and the misuse of early retirement as a way of getting rid of older workers; it is possible to argue that this is a voluntary process and that, often, workers will volunteer for early retirement. It is also possible to argue that early retirement policies are a manifestation of how age discrimination has become an acceptable method of reducing the size of a workforce.

However, based on the literature review, this research develops a conceptual framework of factors influencing the financial planning for retirement. This framework emphasizes on those variables like Salary/Income, Culture and Attitude. These independent variables are positively related to the financial planning for retirement. The detailed diagram framework is given below.

From the above diagram (Fig. 1), we can see the linkage among exogenous variables. Individually, each independent variable (eg. Income/salary, culture, attitude) is affecting dependent variable of financial planning after retirement. Basically, with this estimating relationship among variables, the hypotheses can be constructed. To test our variables we construct the following hypotheses:

H1: Income/Salary is significant with financial planning for retirement

H2: Culture does have some significance with financial planning for retirement

H3: Attitude is related with financial planning for retirement

\section{MATERIALS AND METHODS}

Since the major purpose of the study is to examine factors that influence financial planning after retirement, a self-structured questionnaire was developed to collect the required primary data from the Malaysian public in Selangor state. The survey questionnaire consists of 3 distinct sections, each of which contains relevant questions pertaining to different parts of the study. The first section focuses on the socio-demographic status of the respondents (age, sex, ethnicity, religion, marital status, educational level). This is in addition to other general questions regarding the competitive environment and demographic information, such as plan of the respondent, features of the financial planning, retirement planning, working capacity, incentives after retirement age and current situation of job market and financial market. The last two sections addressed the primary objective of the study. A 7-point scale was used ranging from 'strongly disagree' to 'strongly agree' for the two sections in the questionnaire. A pilot test was conducted to validate the research instrument The questionnaires were then systematically distributed using a simple random sampling method administered on walk-in customers at market places, educational institutions, pedestrians' walk-ways, government and private institutions. The respondents comprised mostly the Malays, Chinese and Indians. A sample size of 200 resp[ondents were identified for the survey out of which 170 questionnaires were received. The data were then screened and only 150 responses were considered complete and valid for data analysis. This represents a success rate of $88 \%$, which is considered to be extremely good in view of the time, cost, certainty and geographical constraints. Factor analysis was used in the study to identify the salient attributes that have impact on factors influencing the iinancial planning after retirement. Since factor analysis represents an analytical process of transforming statistical data (as measurements) into linear combinations of variables, it is a meaningful statistical method used for combining a large number of data into a considerably smaller number of factors with a minimum loss of information (Hair et al., 1992). In addition, Structural Educational Modeling (SEM) had been carried out to investigate the relationship among the variables which influence financial planning after retirement.

\section{RESULTS AND DISCUSSION}

\subsection{Reliability Coefficient}

In order to measure the reliability for a set of two or more constructs, the Cronbach's alpha is a commonly used method where alpha coefficient values range between 0 and 1 with higher values indicating higher reliability among the indicators (Hair et al., 1992). Hence, 1 is the highest value that can be achieved (Table 1). In accordance with the Cronbach's alpha test, the total scale of reliability for this study varies from 0.90 to 0.98 , indicating an overall higher reliability factors. The reliability of this study is substantial in every respect, as the highest reliability value that can be achieved is 1.0 . 
Table 1. Reliability analysis for all variables

\begin{tabular}{lll}
\hline Cronbach's alpha & $\begin{array}{l}\text { Based on standardized items } \\
\text { Cronbach's alpha }\end{array}$ & N of items \\
\hline 0.903 & 0.906 & 20 \\
\hline
\end{tabular}

Table 2. KMO and bartlett's test

\begin{tabular}{llr}
\hline Kaiser-Meyer-Olkin & & 0.838 \\
Measure of sampling adequacy & & \\
Bartlett's Test of Sphericity & Approx. & \\
& Chi-Square & 973.734 \\
& df & 91.000 \\
& Sig. & 0.000 \\
\hline
\end{tabular}

Table 3. Factor loading matrices following rotation of threefactor solutions

\begin{tabular}{|c|c|c|c|}
\hline Descriptions & F1 & F2 & F3 \\
\hline Income/Salary & & & \\
\hline $\begin{array}{l}\text { Higher income leads to } \\
\text { proper financial planning. }\end{array}$ & & 0.772 & \\
\hline $\begin{array}{l}\text { Limited income makes me } \\
\text { think about financial planning. }\end{array}$ & & 0.743 & \\
\hline $\begin{array}{l}\text { Culture and government responsibility } \\
\text { improve financial planning. }\end{array}$ & & 0.691 & \\
\hline $\begin{array}{l}\text { Income is an influential } \\
\text { factor for financial planning. }\end{array}$ & & 0.688 & \\
\hline $\begin{array}{l}\text { More income would result in } \\
\text { proper financial planning. }\end{array}$ & & 0.672 & \\
\hline Culture influences my financial planning. & & 0.668 & \\
\hline $\begin{array}{l}\text { Lack of financial planning } \\
\text { creates trouble after retirement. } \\
\text { Attitude }\end{array}$ & & 0.595 & \\
\hline $\begin{array}{l}\text { Initiate financial planning } \\
\text { as early as possible. }\end{array}$ & 0.825 & & \\
\hline $\begin{array}{l}\text { Initiate financial planning } \\
\text { while studying. }\end{array}$ & 0.808 & & \\
\hline $\begin{array}{l}\text { Financial planning helps in leading a } \\
\text { prosperous life after my retirement. }\end{array}$ & 0.789 & & \\
\hline $\begin{array}{l}\text { Financial planning creates the burden of } \\
\text { saving money immediately. } \\
\text { Culture }\end{array}$ & 0.655 & & \\
\hline $\begin{array}{l}\text { My family encourages me to make } \\
\text { financial planning. }\end{array}$ & & & 0.853 \\
\hline $\begin{array}{l}\text { The local culture encourages } \\
\text { nuclear family structure, which }\end{array}$ & & & \\
\hline $\begin{array}{l}\text { leads to a proper financial } \\
\text { planning after retirement. }\end{array}$ & & & 0.808 \\
\hline $\begin{array}{l}\text { The local people are reluctant about their } \\
\text { financial planning after retirement }\end{array}$ & & & 0.680 \\
\hline
\end{tabular}

Table 4. Reliability coefficients for derived factors

\begin{tabular}{llll}
\hline \multicolumn{4}{l}{ Table 4. Reliability coefficients for derived factors } \\
Factor & $\begin{array}{l}\text { No. of } \\
\text { cases }\end{array}$ & $\begin{array}{l}\text { No. of } \\
\text { items }\end{array}$ & $\begin{array}{l}\text { Cronbach's } \\
\text { alpha }\end{array}$ \\
\hline Income/salary & 150 & 7 & 0.843 \\
Culture & 150 & 3 & 0.825 \\
Attitude & 150 & 4 & 0.819 \\
\hline
\end{tabular}

\subsection{Factor Analysis}

The results obtained from 150 respondents were thoroughly analyzed and the outputs of the results have been clearly explained. Applying SPSS, the Principal Component Analysis (PCA) was carried out to explore the underlying factors associated with 14 items. The constructs validity was tested using Bartlett's Test of Sphericity and The Kaiser-Mayer-Olkin Measure of sampling adequacy analyzing the strength of association among variables. As rule of thumb states, the overall KMO value should be 0.60 or higher to perform factor analysis. If this is not achieved, then it is necessary to drop the variables with the lowest anti image value until the KMO overall rises above 9.60. The results for the Bartlett's Test of Sphericity and the KMO revealed that both were highly significant and eventually it was concluded that this variable was suitable for the factor analysis (Table 2).

The factor analysis draws a distinction regarding factors. However, deciding upon the number of factors that can be retained is difficult but initial runs based on eignen values showed three factors. To determine the minimum loading necessary to include an item in its respective constructs, Hair et al. (1992) suggested that variables with loading greater than 0.30 is considered significant, loading greater than 0.40 is more important and loading 0.50 or greater is very significant. For this study, the general criteria were accepted on items with loading of 0.40 or greater. Not a single factor had been dropped out under this circumstance which means the factor analysis ran on an ultimate success. The result shown explaining a total variance by the six factors was $63.050 \%$. The values of the following Table 3 indicate the affiliation of the items to a factor. Generally, the factor is the natural affinity of an item for a group. The higher loading (factor) indicates the stronger affiliation of an item to a specific factor. The findings of this study indicate that each of the three dimensions (Income/Salary, Attitude, (Culture) was homogeneously loaded into the different factors, which means each of the dimensions that were loaded into three different factors.

\subsection{Reliability Test}

Reliability is the degree to which the observed variable measures the "true" value and is "error free"; thus, it is the opposite of measurement error. If the same measure is asked repeatedly, for example, more reliable measures will show greater consistency than less reliable measures (Hair et al., 1992). The coefficient alpha estimates for the multi-item scales used in this study are presented in Table 5. Reliability coefficients (Cronbach's Alpha) were computed for the items that formed each factor. The reliability coefficients for the three factors, namely, Income/Salary, Attitude, Culture were 0.843, 0.819, 0. 825 respectively. As Table 5 shows, all alpha coefficients for the data exceed the minimum standard for reliability of 0.70 as recommended by Nunally and Bernstein (2010) for basic research. Thus, the results indicate that these multiple measures are highly reliable for measuring each construct. 


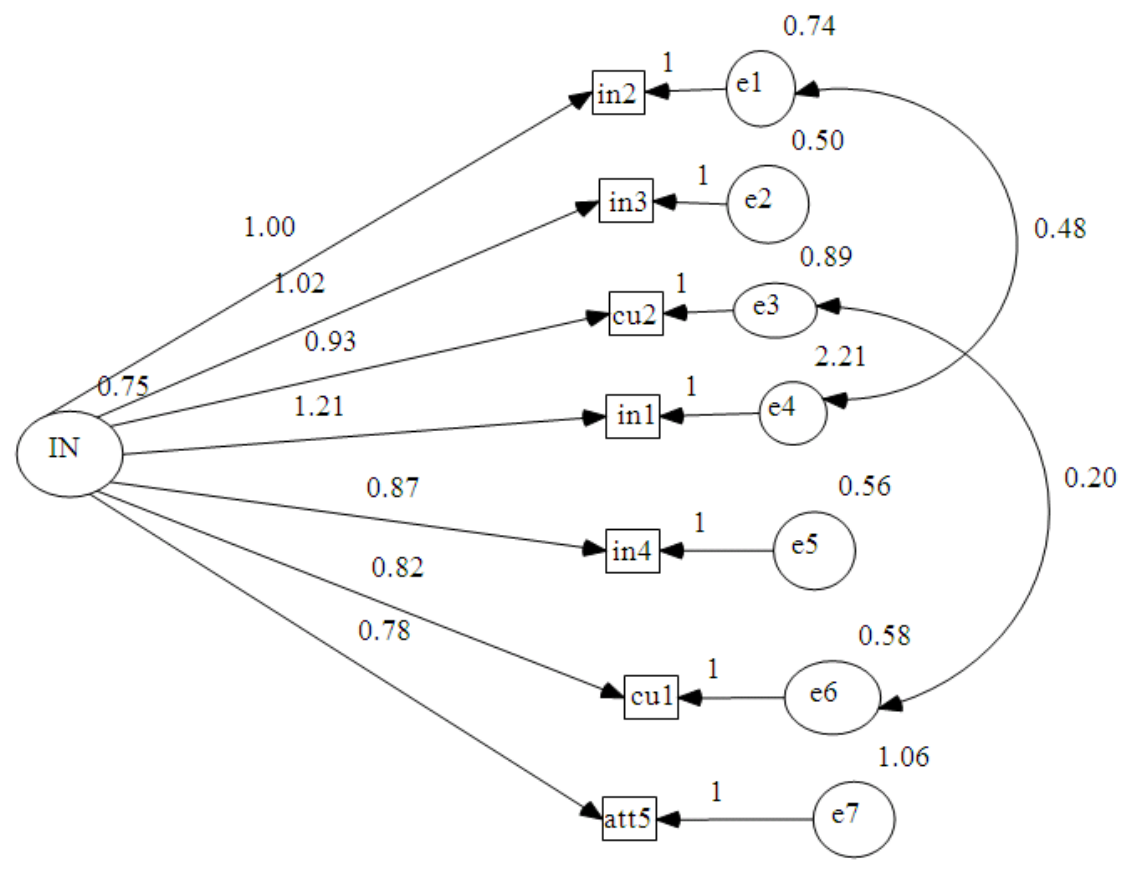

Fig. 2. Confirmatory factor analysis for income or salary

Table 5. Standard estimation of the main model

\begin{tabular}{lllll}
\hline Standardized regression weight & Estimate & S.E. & C.R. & P value \\
\hline H1: Income (IN) $\leftarrow$ Financial Planning (FP) & 0.358 & 0.091 & 3.934 & 0.000 \\
H2: Culture (Cul) $\leftarrow$ Financial Planning (FP) & 0.251 & 0.076 & 3.304 & 0.000 \\
H3: Attitude (Att) $\leftarrow$ Financial Planning (FP) & 0.214 & 0.106 & 3.217 & 0.000 \\
\hline
\end{tabular}

\subsection{Confirmatory Factor Analysis}

Factor analysis assumes that the covariance between a set of observed variables can be explained by a smaller number of underlying latent factors. In exploratory factor analysis, we proceed as if we had no hypothesis about the number of latent factors and the relations between the latent factors and the observed variables. Statistical procedures are used to estimate the number of underlying factors and to estimate the factor loadings. In exploratory factor analysis, the model is arbitrary: all variables load on all factors. Typically in our study a transformation method such as Varimax rotation was used to improve the interpretation result. In contrast, the path diagram will be utilized that will represent a clear hypothesis about the factor structure. Models of this kind are called restricted or Confirmatory Factor Analysis (CFA) models. CFA is actually the measurement part of Structural Equation Modeling (SEM). Although we had done an EFA for verifying grouping and loading pattern of measuring scale items, we further attempted to screen our EFA examination by conducting a CFA among all the exogenous variables (Income/salary, Attitude, Culture) with measuring items retained by the EFA.

\subsection{Income/Salary}

For Income/salary, the modification indices for the covariance of measurement errors were: 10.544 between cu2 ("Culture and government responsible for improvement of financial planning") and cul ("Culture influences my financial planning") and 17.799 between In 2 and In1 ("Higher income leads to proper financial planning" and "Income is an influential factor in the financial planning"). These two sets of measurement error are logically conceivable to be correlated (Fig. 2). Therefore these correlated relations were allowed in the model. Each pair was added to the measurement model one at a time. After adding these three parameters, testing of the revised measurement model showed:

$\chi^{2} /$ d.f. $=1.297\left(\chi^{2}=15.568\right.$, d.f $\left.=12\right)$;

$\mathrm{GFI}=0.972$, $\mathrm{AGFI}=0.934, \mathrm{CFI}=0.991$,

$\mathrm{NFI}=0.962$ and $\mathrm{RMSEA}=0.045$ 
Md. Abdul Jalil et al. / American Journal of Applied Sciences, 10 (3): 270-279, 2013

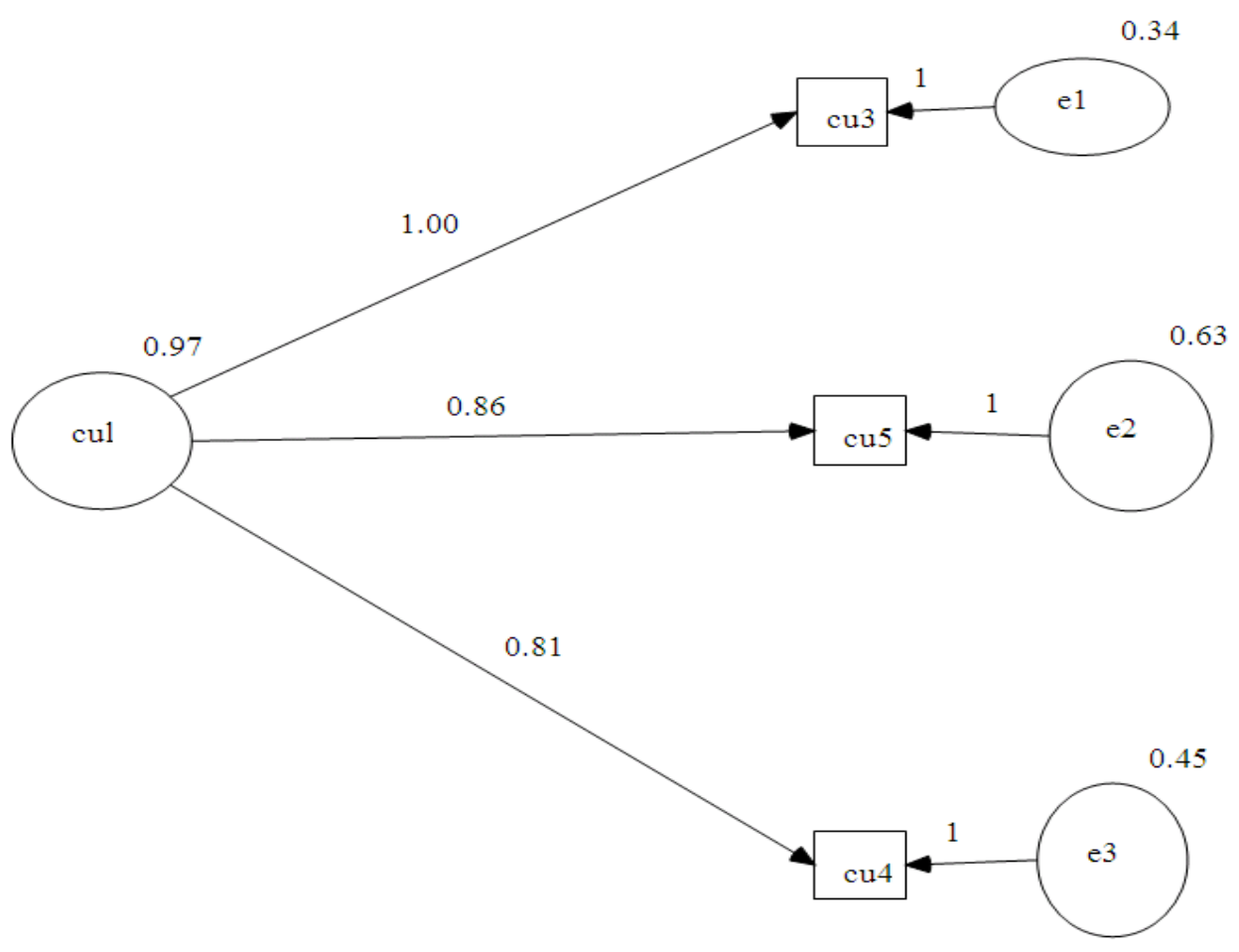

Fig. 3. Confirmatory factor analysis for culture

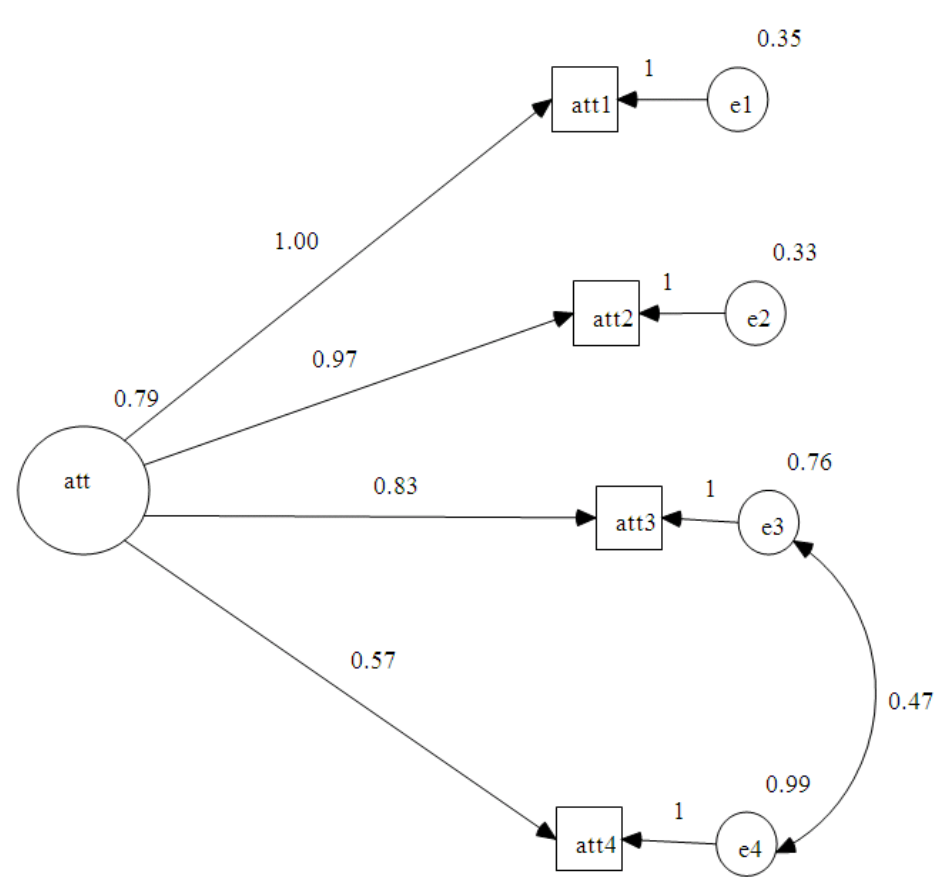

Fig. 4. Confirmatory factor analysis for attitude 


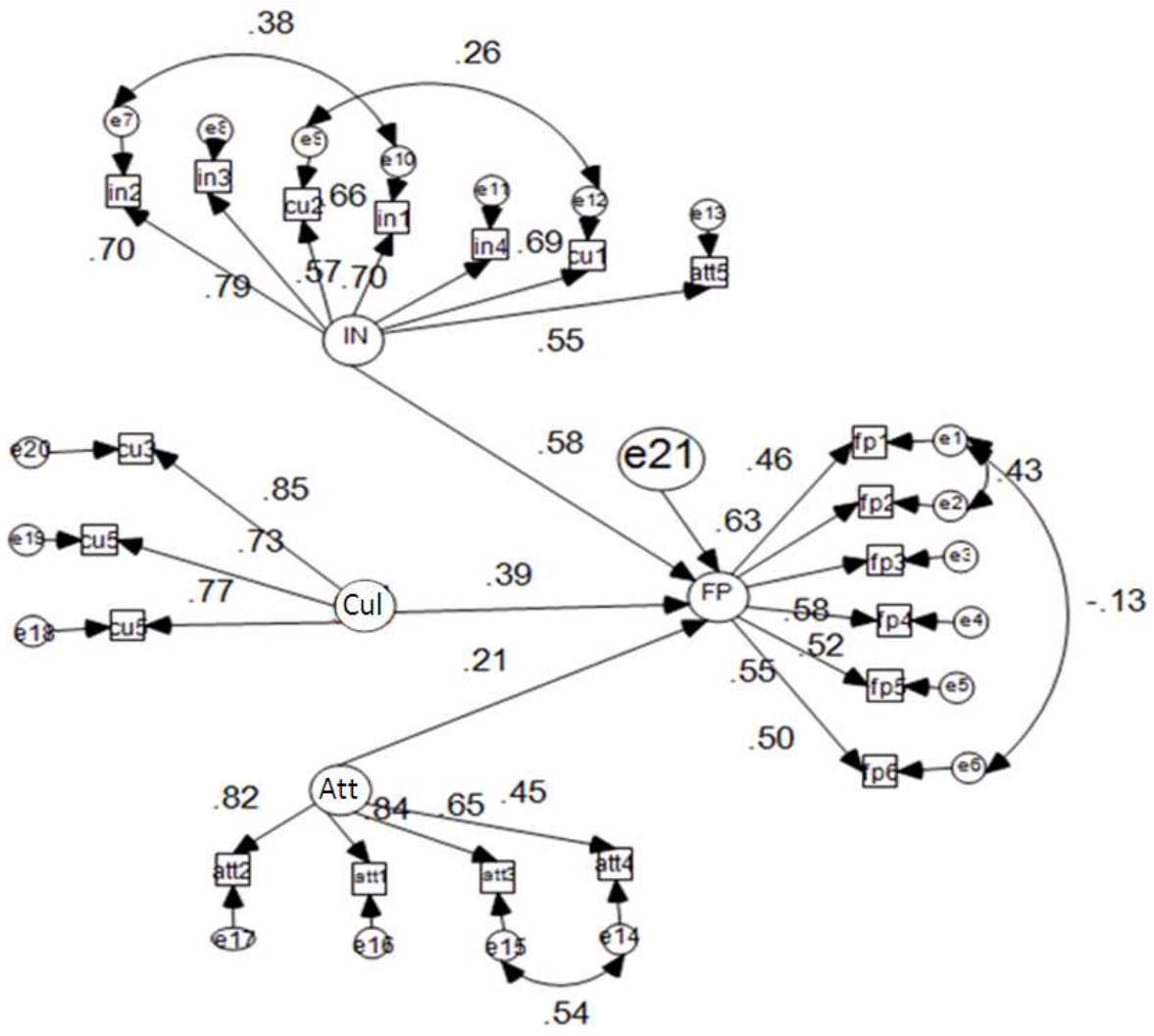

Fig. 5. Factors Influencing Financial Planning after Retirement Model (For Total Sample)

\subsection{Culture}

From our EFA as shown in Table 4 we have retained 3 measuring items for culture. We could retain all these items after conducting a CFA, as all those indicators were loaded with loading factor more than 0.50 . The fit indices from the default measurement model were: $\chi^{2}=$ 0.000 , d.f $=0$ (Probability level cannot be computed as the model has zero degrees of freedom). The model should fit the data perfectly and the chi-square statistic should be zero. Consequently, no probability level can be assigned to the chi-square statistic. As reffered to Fig. 3, GFI = $1.00, \mathrm{CFI}=1.00, \mathrm{NFI}=1.00$ and $\mathrm{RMSEA}=0.607$. All indices represent an adequate fit of the model, except the value of RMSEA, thus, there was no need to examine the modification indices.

\subsection{Attitude}

From our EFA as shown in Table 4 we have retained 4 measuring items for attitude. We could retain all these items after conducting a CFA, The default model fit indices of attitude were adequate; only the RMSEA, however was larger than expected $(p<0.05)$. The examination of the modification indices revealed that the measurement errors of 32.479 between Att3 ("Financial planning will help to lead a prosperous life after my retirement") and Att4 ("Financial planning is a burden to save the money from now") were correlated. The Logical possibility for the correlation was allowed; therefore, these measurement errors were allowed to be related (Fig. 4). After adding this parameter, the measurement model fit indices of attitude showed an adequate fit.

$\chi^{2} /$ d.f. $=0.079\left(\chi^{2}=0.079\right.$, d.f $\left.=1\right) ;$

$\mathrm{GFI}=1.00, \mathrm{AGFI}=0.997, \mathrm{CFI}=1.00$,

$\mathrm{NFI}=1.00$ and $\mathrm{RMSEA}=0.000$

However, a Structural Equation Modeling (SEM) was performed to test the hypothesized model using the AMOS 7. SEM is known as a latent variable analysis or causal modeling as it provides parameter estimates of the direct and indirect links between observed variables. In Fig. 5 boxes represent manifest or measured variables, 
whereas circles indicate latent or unobserved variables. As shown in Fig. 5 the model's exogenous variables (Income $=\mathrm{IN}$, Culture $=\mathrm{Cul}$, Attitude $=$ Att) were measured by $\mathrm{X}$ variable. There are seven indicators used for the construct of Income or salary (IN); four indicators used for the construct of Attitude (Att); three indicators used for the culture Construct (Cul). Similarly, the model's endogenous variables were measured by $\mathrm{Y}$ (Financial planning perception) variable. Six indicators measured the construct of customers' Perception (FP).

\subsection{Statistical Significance of Parameter Estimates}

The test statistic here is the Critical Ratio (CR), which represents the parameter estimate divided by its standard error and, as such, it operates as a z-statistic in testing as the estimate is statistically different from zero. Based on a probability level 0.05 , the test statistic then needs to be $> \pm 1.96$ before the hypothesis (that estimates equals 0.0 ) can be rejected. Non-significant parameters, with the exception of error variances, can be considered as unimportant to the model; in the interest of scientific parsimony, albeit given an adequate sample size, they should be deleted from the model. On the other hand, it is important to note that non-significant parameters can be indicative of a sample size that is too small (Byrne, 2001).

\subsection{Hypotheses Testing}

The structural equation model was examined to test the relationship among constructs. The goodness-of-fit indicators for this model were chi-square/df = $(306.937 / 162)=1.894, \mathrm{GFI}=0.839, \mathrm{AGFI}=0.792, \mathrm{CFI}$ $=0.882$, NFI $=0.784$. Figure 5 depicts the full model. Of the three paths hypothesized in the model, all the paths were significant at $\mathrm{p}<0.05$. (H1) Income or monthly salary directly effects a person's perceptions in the financial planning after retirement. Regarding the $\mathrm{H} 2$ : The culture of a particular individual in which he or she has grown up has a direct effect on a person's perceptions in financial planning after retirement. Our results also revealed that the culture factor has a positive effect on perceptions on the financial planning after retirement. Therefore, our hypothesis is accepted at $p=$ 0.000 which shows that the relationship is highly significant. The result also showed that an individual's attitude emerges as the important factor which affects the person's financial planning after retirement. The study shows that attitude has a positive impact on the individual's perceptions on a financial planning after retirement. Therefore, our hypothesis $\mathrm{H} 3$ is also accepted as $p=0.000$ is showing the highly significance. Among all the significant variables, from our result, people's income or salary is the most important factor among our respondents followed by culture and attitude.

\section{CONCLUSION}

\subsection{Conclusion, Limitation and Implication}

The significance of financial planning is a noteworthy issue for intellectual milieu which partially stimulates the country's business growth, economic expansion and modern development. The financial planning after retirement in Malaysia has been much enhanced by the financial planners and general public nowadays where knowledge, learning, attitude and culture are being focused on thoughtfully by the business community today. However, little attempt has been conducted to provide a comprehensive evidence in measuring the perception towards financial planning after retirement. We have further explored the factors, for instance, the individual's monthly salary; the individual's surrounding culture and the individual's attitude which mostly influence their decisions of financial planning after their retirement. This study contributes additional empirical evidence to factors influencing the respondents' financial planning after retirement. The findings will be extremely useful for an effective financial plan in tailoring the needs of individuals based on age, gender, race, marital status, profession, level of income and expenses. It is hoped that the findings of this study contribute to enhance and improve the performance of the financial planner profession and industry in an emerging economy such as Malaysia.

\section{REFERENCES}

Auerbach, J. and L. Kotlikoff, 1991. The adequacy of life insurance purchases. J. Financial Intermed., 1: 215-241. DOI: 10.1016/1042-9573(91)90008-N

Barber, B. and T. Odean, 2001. Boys will be boys: gender, overconfidence and common stock investment. Q. J. Econ., 116: 261-292. DOI: $10.1162 / 003355301556400$

Bernheim, B.D., 1987. Social Security Benefits: An Empirical Study of Expectations and Realizations. National Bureau of Economic Research, Cambridge, MA.

Bernheim, D., 1995. Do households appreciate their financial vulnerabilities? An Analysis of Actions, Perceptions and Public Policy. Tax Policy and Economic Growth. Washington, DC. 
Bernheim, D., 1998. Financial Illiteracy, Education and Retirement Saving. In: Living With Defined Contribution Pensions: Remaking Responsibility for Retirement, Mitchell, O.S. and S.J. Schieber (Eds.), University of Pennsylvania Press, Philadelphia, ISBN-10: 0812234391, pp: 299.

Byrne, B.M., 2001. Structural Equation Modeling with Amos: Basic Concepts, Applications and Programming. 1st Edn., Routledge, ISBN-10: 0805841040, pp: 338.

Calvert, L. C. John and S. Paolo, 2005. Down or Out: Assessing the Welfare Costs of Household Investment Mistakes. Harvard University.

Fleiss, A., 1985. Home Ownership Alternatives for the Elderly. 1st Edn., H.M.S.O., London, ISBN-10: 0117517933, pp: 164.

Gregory, R.F., 2001. Age Discrimination in the American Workplace. 1st Edn., Rutgers University Press, New Brunswick, ISBN-10: 0813529069, pp: 283.

Hair, J.F., R.E. Anderson, R.L. Tatham and W.C. Black, 1992. Multivariate Data Analysis. 3rd Edn., Macmillan, New York.

Hilgerth, M.A., J.M. Hogarth and S.G. Beverly, 2003. Household financial management: The connection between knowledge and behavior. Fed. Res. Bull.

Hogarth, J.M. and M.A. Hilgert, 2002. Financial Knowledge, Experience and Learning. 4th Edn., Barron's Finance, pp: 578.

Hurd, M.D., 1990. Research on the elderly: Economic status, retirement and consumption and saving. J. Econ. Literat., 28: 565-637.

James, W., H. Leavell and B. Maniam, 2002. Financial planning, managers and college students. Managerial Finance, 28: 35-42. DOI: $10.1108 / 03074350210767960$
Kennickell, A.B., M. Starr-McCluer and A.E. Sunden, 1996. Saving and financial planning: Some findings from a focus group. IDEAS.

Lim, K.G., 2003. An empirical study of older workers' attitudes towards the retirement experience. Employee Relat., 25: 330-346. DOI: 10.1108/01425450310483361

Nunally, J.C. and I.H. Bernstein, 2010. Psychometric Theory. 3rd Edn., Tata McGraw-Hill Education, New Delhi, ISBN-10: 0071070885, pp: 752.

Peace, S.M. and C. Holland, 2001. Inclusive Housing in an Ageing Society: Innovative Approaches. 1st Edn., Policy Press, Bristol, ISBN-10: 1861342632 , pp: 272.

Richman, L.S., 1993. How Americans can save more. Fortune, 102: 108-112.

Rolfe, S., S. Mackintosh and P. Leather, 1995. Retirement housing: Ownership and independence: A survey of residents of guardian housing schemes. Anchor Housing Association.

Sargeant, M., 2004. Mandatory retirement age and age discrimination. Employee Relat., 26: E151-E166. DOI: $10.1108 / 01425450410511061$

SNP, 2000. Census of population advanced data release. Singapore National Printers, Singapore.

Williams, G., 1990. The Experience of Housing in Retirement: Elderly Lifestyles and Private Initiative. 1st Edn., Avebury, Aldershot u.a., ISBN-10: 056607091X, pp: 239. 